\title{
Analisis Rugi-Rugi Panas Pada TANGKi Penyimpan Panas DALAM SISTEM PEMBANGKIT LISTRIK TENAGA MATAHARI
}

\author{
Ghalya Pikra, Agus Salim, Tri Admono, Merry Indahsari Devi \\ Pusat Penelitian Tenaga Listrik dan Mekatronik - LIPI \\ Komp LIPI Bandung , Jl. Sangkuriang, Gd. 20. Lt. 2, Bandung, \\ Jawa Barat 40135, Indonesia \\ ghalyapikra@yahoo.com; agus.salim35@yahoo.com; januar35@yahoo.com; merry_devi@yahoo.com
}

Diterima: 19 Agustus 2010; Direvisi: 23 September 2010; Disetujui: 30 September 2010; Terbit online: 10 Oktober 2010.

\begin{abstract}
Abstrak
Analisis rugi-rugi panas pada tangki penyimpan panas dalam sistem pembangkit listrik tenaga matahari dimaksudkan untuk mengetahui nilai panas yang hilang selama dilakukan penyimpanan. Pemilihan bahan isolasi, tebal isolasi, waktu penyimpanan dan fluida penyimpan panas mempengaruhi nilai rugi-rugi panas. Penelitian diawali dengan menentukan dimensi dan bahan tangki beserta isolasinya, serta menentukan waktu penyimpanan panas di dalam tangki. Fluida dan temperatur operasi ditentukan untuk mendapatkan spesifikasi fluida yang akan digunakan sebagai data analisis. Analisis diawali dengan perhitungan kapasitas penyimpanan, dilanjutkan dengan pembuatan jala-jala termal untuk mendapatkan persamaan tahanan termal yang kemudian digunakan untuk menghitung rugi-rugi panas pada tangki. Hasil perhitungan menunjukkan bahwa tangki penyimpan panas dengan diameter 0,4 $\mathrm{m}$ dan tinggi 0,45 $\mathrm{m}$ serta isolasi menggunakan ceramic fiber wool dengan tebal 0,1 m, maka nilai rugirugi panas yang dihasilkan adalah 63,43 W.
\end{abstract}

Kata kunci: pembangkit listrik tenaga matahari, tangki penyimpan panas, ceramic, rugi-rugi panas.

\begin{abstract}
Analysis of heat loss on heat storage tank in solar power generation system is intended to determine the heat loss value during storage. Selection of insulation material, insulation thickness, time of storage and heat storage fluid affects the heat losses. The research was initiated by determining the dimension of the tank and its insulation material, and determining the heat storage time in the tank. Fluid and operating temperature is determined to get the fluid specification to be used as data analysis. The analysis begins with the calculation of storage capacities, followed by making of thermal nets to get the thermal resistance equation which is then used to calculate the heat loss in the tank. The result shows that the heat storage tank with $0.4 \mathrm{~m}$ diameter and $0.45 \mathrm{~m}$ height and uses ceramic fiber wool insulation with $0.1 \mathrm{~m}$ thickness gives the value of heat loss of $63.43 \mathrm{~W}$.
\end{abstract}

Keywords: solar power plants, heat storage tank, ceramic, heat loss.

\section{Pendahuluan}

Energi matahari merupakan sumber energi yang paling banyak di bumi. Konversi energi matahari menjadi energi panas yang kemudian menghasilkan listrik adalah aplikasi energi matahari yang paling penting. Wu, Reddy dan Rogers menyatakan bahwa energi yang berasal dari matahari perlu disimpan karena ketersediaan energi matahari tergantung pada waktu, kondisi cuaca, dan garis lintang, dimana permintaan listrik bervariasi tergantung waktu [1]. Energi ini dapat disimpan sebagai energi termal atau listrik. Penyimpanan energi termal merupakan teknologi yang penting untuk efisiensi energi. Oleh karena itu, penyimpanan energi termal dianggap sebagai metode yang ekonomis [2].

Tiga komponen utama pemanfaatan sistem energi termal matahari terkonsentrasi adalah collector energi matahari, sistem penyimpanan energi, dan steam generator yang digunakan untuk menggerakkan turbin untuk membangkitkan listrik. Solar Collector digunakan sebagai pengumpul panas dari matahari yang kemudian digunakan untuk memanaskan fluida didalam receiver atau absorber. Sistem penyimpanan energi berfungsi untuk menciptakan efisiensi energi. Steam generator disini adalah sebagai penghasil uap untuk menggerakkan turbin.

Pada sistem pembangkit listrik tenaga matahari terkonsentrasi, panas matahari dikumpulkan dalam pengumpul panas matahari berbentuk parabolic yang disebut Parabolic Trough Solar Collector. Panas matahari tersebut nantinya diteruskan ke suatu receiver yang didalamnya dialiri oleh suatu fluida (Heat Transfer Fluid/HTF) yang kemudian akan meneruskan panas yang diterima oleh receiver 
menuju steam generator sebagai penghasil uap yang digunakan untuk menggerakkan turbin uap untuk menghasilkan energi listrik. Sebagian fluida di dalam receiver/absorber kemudian dialirkan ke tangki penyimpanan panas (heat storage) untuk disimpan dan akan digunakan saat malam hari atau ketika tidak ada matahari. Sistem pembangkit listrik tenaga matahari terkonsentrasi seperti ditunjukkan pada Gambar 1 dibawah ini.

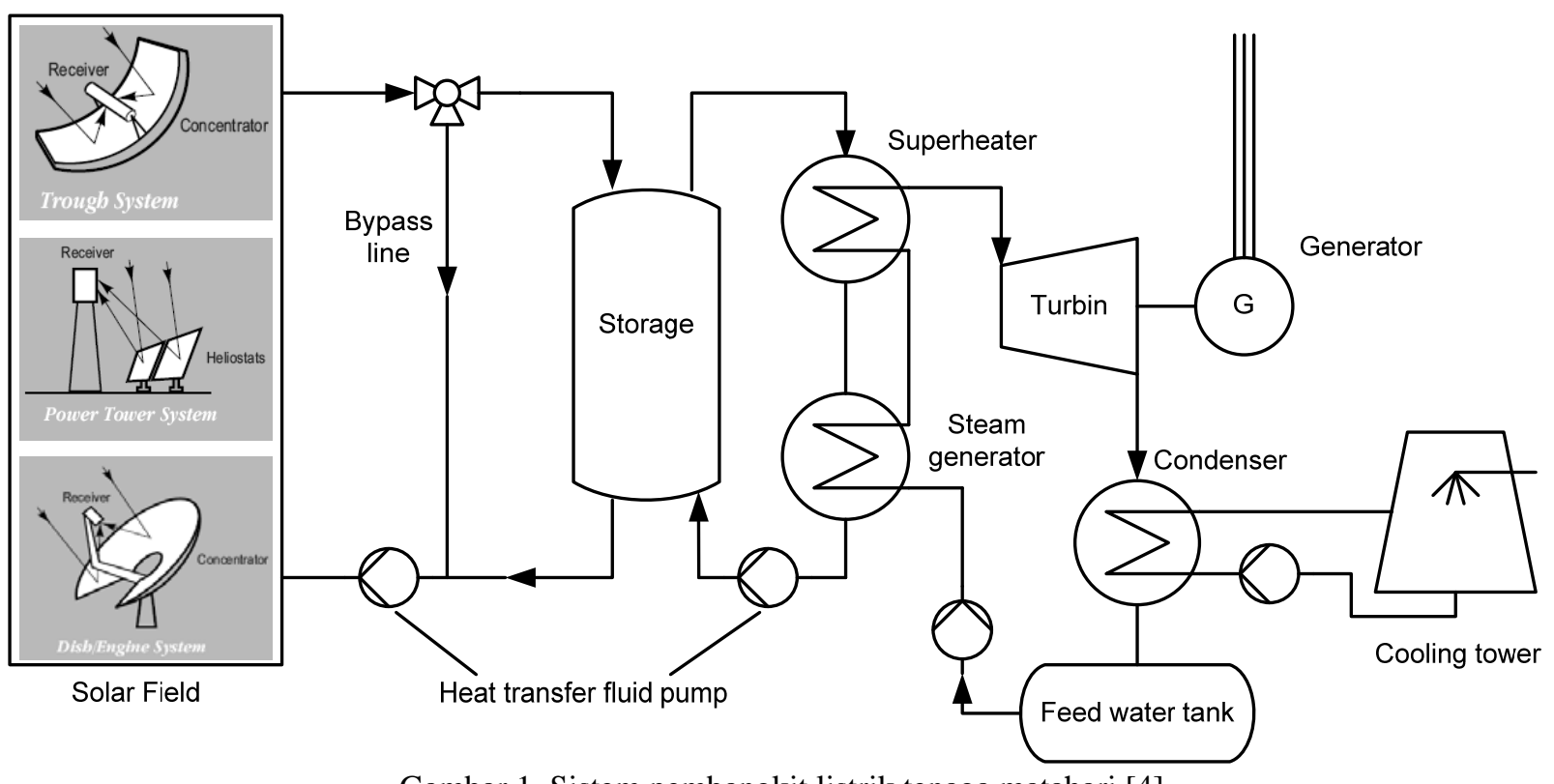

Gambar 1. Sistem pembangkit listrik tenaga matahari [4].

Pembangkit listrik tenaga matahari menggunakan parabolic trough memerlukan sistem penyimpanan panas sensibel dengan temperatur operasi antara $300^{\circ} \mathrm{C}$ sampai $390^{\circ} \mathrm{C}$. Thermal oil telah banyak digunakan sebagai fluida perpindahan panas untuk mencapai temperatur tersebut. Semakin besar nilai spesifikasi panas yang dimiliki oleh fluida maka nilai kapasitas penyimpanan panasnya akan semakin besar pula, yang artinya fluida tersebut memiliki kemampuan menyimpan panas yang baik.

Selain fluida penyimpan panas, nilai rugi-rugi panas dipengaruhi juga oleh bahan isolasi, tebal isolasi, serta waktu penyimpanan panas di dalam tangki. Bahan isolasi dengan nilai konduktivitas termal rendah memiliki kemampuan untuk mengurangi terjadinya kehilangan panas yang besar. Selain itu, semakin tebal isolasi yang digunakan maka semakin rendah nilai rugi-rugi panas yang terjadi, dan semakin lama waktu yang dibutuhkan untuk menyimpan panas, maka akan semakin besar nilai rugi-rugi panas yang terjadi.

Bahan tangki penyimpan panas terbuat dari pelat stainless steel, kemudian dilapisi oleh pelat besi dan dilapisi lagi oleh ceramic dan alumunium foil. Ceramic dipilih sebagai isolasi karena memiliki kestabilan fisik dan termal hingga $1100^{\circ} \mathrm{C}$, kekuatan tarik yang tinggi, serta konduktivitas termal rendah. Analisis dilakukan dengan cara menghitung kapasitas penyimpanan panas dan rugi-rugi panas pada tangki penyimpan panas. Selain itu dilakukan juga perhitungan untuk rugi-rugi panas dengan tebal isolasi yang bervariasi dan dengan waktu penyimpanan yang bervariasi.

Makalah ini bertujuan untuk menganalisis rugi-rugi panas pada tangki penyimpan panas dalam sistem pembangkit listrik tenaga matahari untuk mengetahui nilai panas yang hilang selama dilakukan penyimpanan, beserta pembahasan pengaruh besar kecilnya nilai rugi-rugi panas.

\section{Metode Analisis}

Analisis diawali dengan menentukan dimensi dari tangki penyimpan panas untuk mengetahui besarnya kapasitas penyimpanan. Tangki penyimpan panas yang didesain untuk menganalisis rugi-rugi panas pada kali ini adalah tangki dengan bentuk silinder dengan diameter tangki dalam sebesar 0,4 $\mathrm{m}$ dan tinggi tangki bagian dalam sebesar $0,45 \mathrm{~m}$. Bahan tangki terbuat dari pelat stainless steel, yang kemudian dilapisi oleh pelat besi dengan tebal $1 \mathrm{~mm}$ yang merupakan pembatas ruang untuk udara dengan tebal $25 \mathrm{~mm}$ antara stainless steel dan pelat besi, kemudian dilapisi oleh ceramic dengan tebal 0,1 $\mathrm{m}$ dan alumunium foil. Tangki dilapisi untuk mengurangi rugi-rugi panas sehingga kemampuan menyimpan panasnya akan baik pula. Gambar desain tangki ditunjukkan pada Gambar 2. 


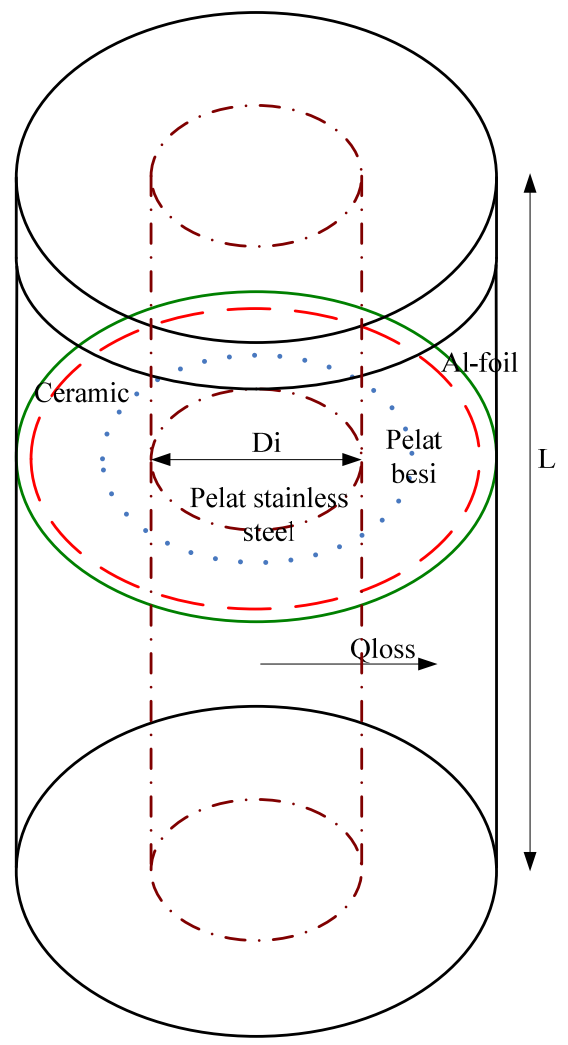

Gambar 2. Tangki penyimpan panas.

Kapasitas penyimpanan tangki dihitung dengan menggunakan persamaan (1) berikut ini.

$$
Q=\rho V C_{p}\left(T_{0}-T_{4}\right)
$$

Dimana $Q$ adalah kalor panas yang disimpan $(\mathrm{kJ}), \rho$ adalah densitas oil $\left(\mathrm{kg} / \mathrm{m}^{3}\right), \quad V$ adalah volume tangki $\left(\mathrm{m}^{3}\right), C p$ adalah panas spesifik fluida $\left(\mathrm{kJ} / \mathrm{kg}^{\circ} \mathrm{C}\right), T_{o}$ adalah temperatur operasi $\left({ }^{\circ} \mathrm{C}\right)$ dan $T_{4}$ adalah temperatur awal $\left({ }^{\circ} \mathrm{C}\right)$.

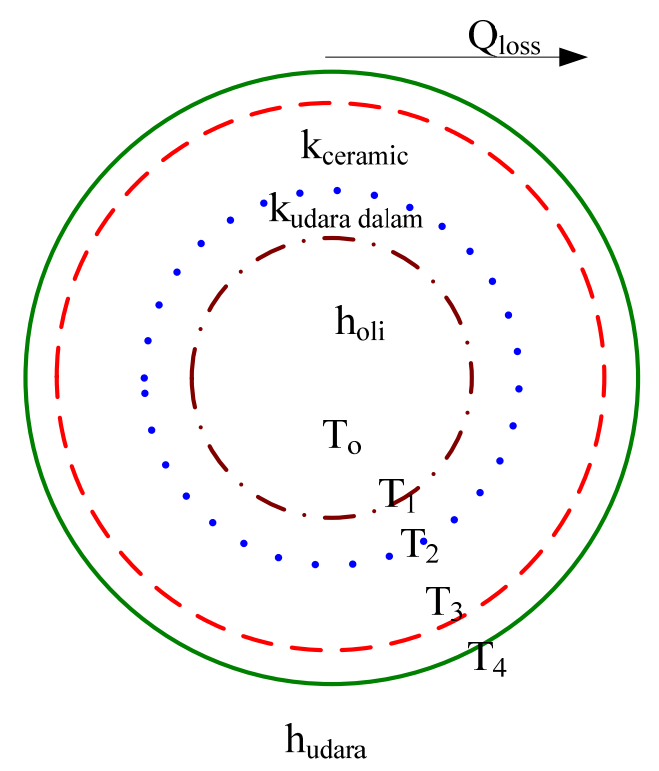

Gambar 3. Skematik gambar laju aliran panas.

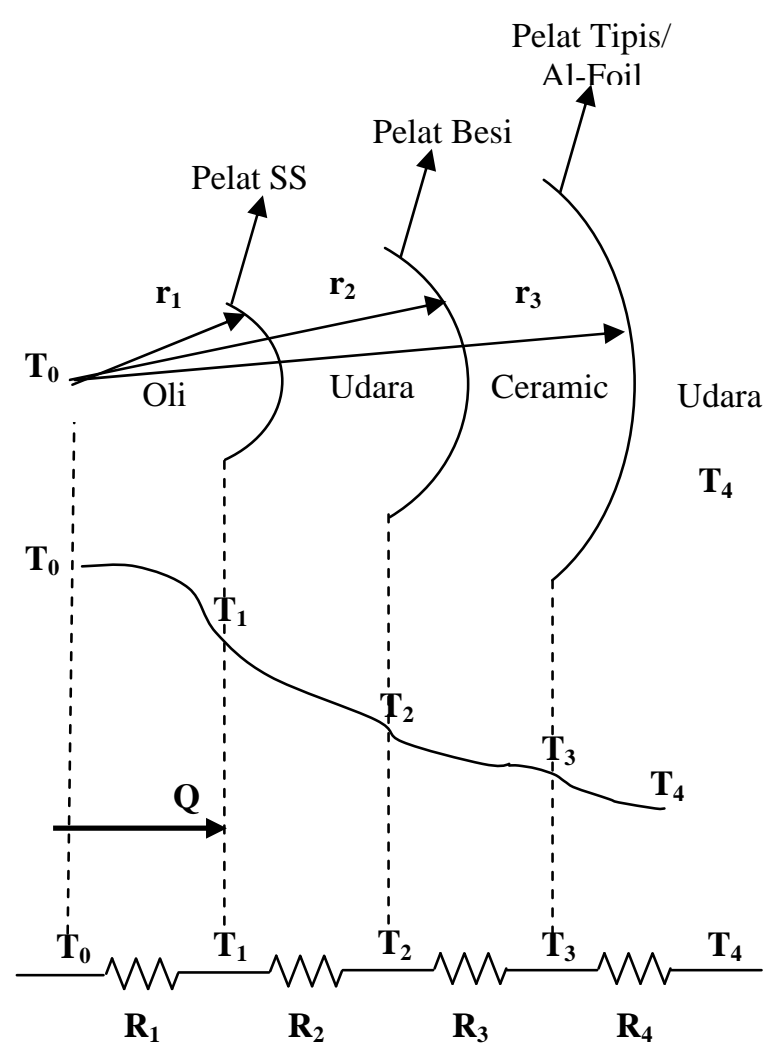

Gambar 4. Jala-jala termal.

Perhitungan rugi-rugi panas diawali dengan membuat skematik gambar laju aliran panas yang dilanjutkan dengan membuat jala-jala termal yang ditunjukkan pada Gambar 3 dan Gambar 4 diatas.

Tahanan termal dihitung untuk mendapatkan rugi-rugi panas yang terjadi di dalam tangki penyimpan panas. Persamaan tahanan termal 1 $\left(R_{l}\right)$ sampai dengan persamaan tahanan termal 4 $\left(R_{4}\right)$ ditunjukkan pada persamaan (2) sampai dengan persamaan (5) berikut ini.

$$
\begin{aligned}
& R_{1}=\frac{1}{h_{H T F} 2 \pi r_{1} L} \\
& R_{2}=\frac{\ln \left(r_{2} / r_{1}\right)}{2 \pi k_{\text {udara }} L} \\
& R_{3}=\frac{\ln \left(r_{3} / r_{2}\right)}{2 \pi k_{\text {ceramic }} L} \\
& R_{4}=\frac{1}{h_{u d^{2}} 2 \pi r_{3} L}
\end{aligned}
$$

Dimana $R_{I}$ adalah tahanan termal dari fluida ke pelat stainless steel $\left({ }^{\circ} \mathrm{C} / \mathrm{W}\right), h_{H T F}$ adalah koefisien konveksi panas pada fluida $\left(\mathrm{W} / \mathrm{m}^{2 \circ} \mathrm{C}\right), r_{l}$ adalah jari-jari tabung bagian dalam (m), $L$ adalah tinggi tabung (m), $R_{2}$ adalah tahanan termal antara pelat stainless steel ke pelat besi $\left({ }^{\circ} \mathrm{C} / \mathrm{W}\right), r_{2}$ adalah jari- 
jari pusat ke ceramic bagian dalam (m), $k_{\text {udara }}$ adalah konduktivitas termal dari udara $\left(\mathrm{W} / \mathrm{m}^{\circ} \mathrm{C}\right)$, $R_{3}$ adalah tahanan termal antara pelat besi ke ceramic bagian luar/ alumunium foil $\left({ }^{\circ} \mathrm{C} / \mathrm{W}\right), r_{3}$ adalah jari-jari dari pusat ke ceramic bagian luar (m), $k_{\text {ceramic }}$ adalah konduktivitas termal dari ceramic $\left(\mathrm{W} / \mathrm{m}^{\circ} \mathrm{C}\right), R_{4}$ adalah tahanan termal dari alumunium foil ke udara luar $\left({ }^{\circ} \mathrm{C} / \mathrm{W}\right)$ dan $h_{\text {udara }}$ adalah koefisien konveksi panas pada udara luar $\left(\mathrm{W} / \mathrm{m}^{2}{ }^{\circ} \mathrm{C}\right)$.

Persamaan rugi-rugi panas pada tangki penyimpan panas ditunjukkan pada persamaan (6) berikut ini.

$$
Q_{\text {loss }}=\frac{\Delta T}{R_{\text {tot }}}=\frac{\Delta T}{R_{1}+R_{2}+R_{3}+R_{4}}
$$

Dimana $Q_{\text {loss }}$ adalah rugi-rugi panas pada tangki penyimpan panas $(\mathrm{W})$.

Data yang digunakan untuk melakukan analisis rugi-rugi panas pada tangki penyimpan panas ditunjukkan pada Tabel 1.

Tabel 1.

Data perancangan [4], [5], [6].

\begin{tabular}{|l|l|}
\hline \multicolumn{1}{|c|}{ Data } & \multicolumn{1}{|c|}{ Nilai } \\
\hline $\begin{array}{l}\text { Diameter tangki dalam } \\
\left(D_{i}\right)\end{array}$ & $0,4 \mathrm{~m}$ \\
\hline $\begin{array}{c}\text { Tebal pelat besi + ceramic } \\
(x)\end{array}$ & $0,101 \mathrm{~m}$ \\
\hline $\begin{array}{l}\text { Tinggi tangki bagian dalam } \\
(L)\end{array}$ & $0,45 \mathrm{~m}$ \\
\hline $\begin{array}{l}\text { Konduktivitas termal udara dalam } \\
\left(k_{\text {ud-dlm }}\right)\end{array}$ & $0,0407 \mathrm{~W} / \mathrm{m}^{\circ} \mathrm{C}$ \\
\hline $\begin{array}{l}\text { Konduktivitas termal ceramic } \\
\left(k_{\text {cer }}\right)\end{array}$ & $0,07 \mathrm{~W} / \mathrm{m}^{\circ} \mathrm{C}$ \\
\hline $\begin{array}{c}\text { Waktu penyimpanan } \\
(t)\end{array}$ & $12 \mathrm{jam}$ \\
\hline $\begin{array}{l}\text { Konduktivitas termal udara luar } \\
\left(k_{\text {ud-luar }}\right)\end{array}$ & $0,0338 \mathrm{~W} / \mathrm{m}^{\circ} \mathrm{C}$ \\
\hline $\begin{array}{l}\text { Temperatur operasi } \\
(T)\end{array}$ & $250^{\circ} \mathrm{C}$ \\
\hline $\begin{array}{c}\text { Panas spesifik thermal oil } \\
(C p)\end{array}$ & $1,978 \mathrm{~kJ} / \mathrm{kg}^{\circ} \mathrm{C}$ \\
\hline $\begin{array}{c}\text { Densitas thermal oil } \\
(\rho)\end{array}$ & $927,6 \mathrm{~kg} / \mathrm{m}^{3}$ \\
\hline $\begin{array}{c}\text { Konduktivitas thermal oil } \\
\left(k_{\text {oli }}\right)\end{array}$ & $0,111 \mathrm{~W} / \mathrm{m}^{\circ} \mathrm{C}$ \\
\hline
\end{tabular}

Temperatur operasi dengan nilai $250^{\circ} \mathrm{C}$ ditentukan berdasarkan hasil pengujian solar collector, dimana temperatur fluida yang terukur di dalam absorber/receiver mencapai $250^{\circ} \mathrm{C}$. Fluida di dalam tangki penyimpan panas mengalir dari receiver/absorber, sehingga temperatur yang terukur di dalam absorber/receiver dijadikan acuan sebagai temperatur di dalam tangki penyimpan panas untuk menganalisis rugi-rugi panas.

\section{PEMBAhasAN}

Hasil perhitungan yang dimulai dari perhitungan kapasitas penyimpanan panas hingga rugi-rugi panas di dalam tangki penyimpan panas ditunjukkan pada Tabel 2.

Tabel 2.

Hasil perancangan termal.

\begin{tabular}{|l|c|}
\hline \multicolumn{1}{|c|}{ Hasil } & Nilai \\
\hline Jenis fluida & Thermo oil \\
\hline Kalor penyimpanan panas $\left(Q_{\text {input }}\right)$ & $22814,55 \mathrm{~kJ}$ \\
\hline Kapasitas panas $(W)$ & $0,53 \mathrm{~kW}$ \\
\hline Tahanan termal total $\left(R_{\text {tot }}\right)$ & $3,47^{\circ} \mathrm{C} / \mathrm{W}$ \\
\hline Rugi-rugi termal $\left(Q_{\text {loss }}\right)$ & $63,43 \mathrm{~W}$ \\
\hline Persentase kehilangan panas & $12 \%$ \\
\hline
\end{tabular}

Hasil analisis pada Tabel 2 menunjukkan bahwa tangki penyimpan panas memiliki nilai kapasitas penyimpanan panas sebesar 2,112 kW. Hal ini dipengaruhi oleh nilai panas spesifik fluida yang besar, sehingga menghasilkan kapasitas penyimpanan panas yang baik.

Rugi-rugi yang dihasilkan sebesar 63,43 W. Hal ini dikarenakan bahan isolasi yang digunakan (ceramic) memiliki konduktivitas termal $\left(k_{\text {ceramic }}\right)$ yang rendah, sehingga dapat melindungi panas di dalam tangki dengan baik. Oleh karena itu, nilai rugi-rugi panas akan menjadi rendah bila bahan yang digunakan sebagai isolasi memiliki nilai konduktivitas termal yang rendah pula. Selain itu, tebal ceramic dan waktu penyimpanan panas juga menentukan nilai rugi-rugi panas. Nilai rugi-rugi panas terhadap tebal ceramic dan nilai rugi-rugi panas terhadap waktu penyimpanan panas ditunjukkan pada Gambar 5 dan Gambar 6 dibawah ini. 


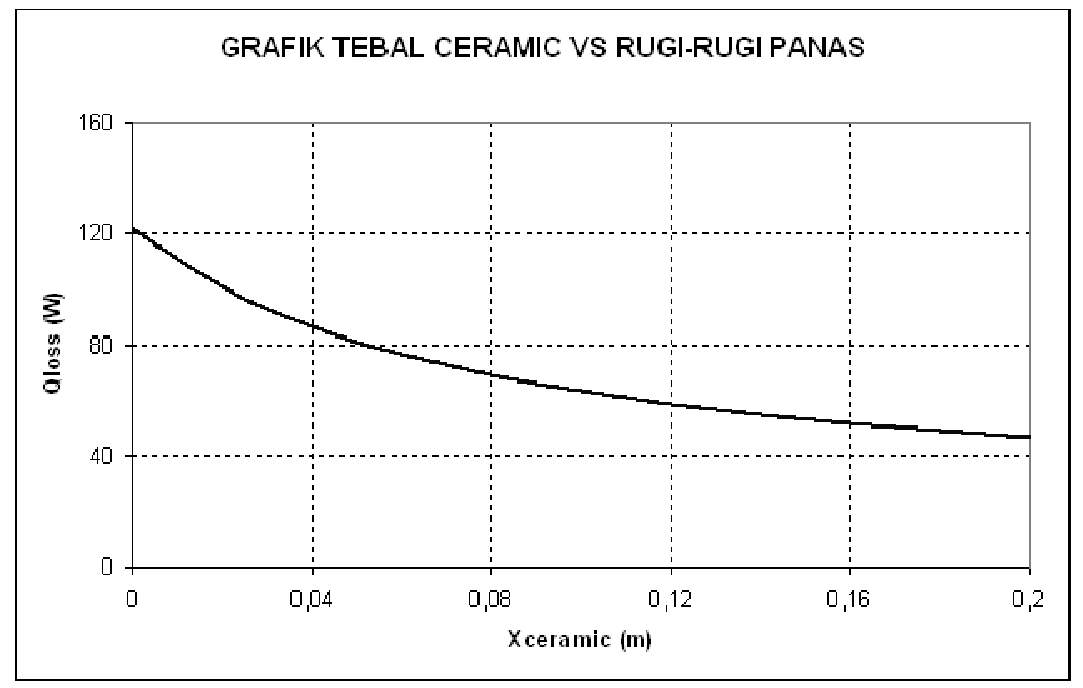

Gambar 5. Grafik tebal ceramic vs $Q_{\text {loss }}$.

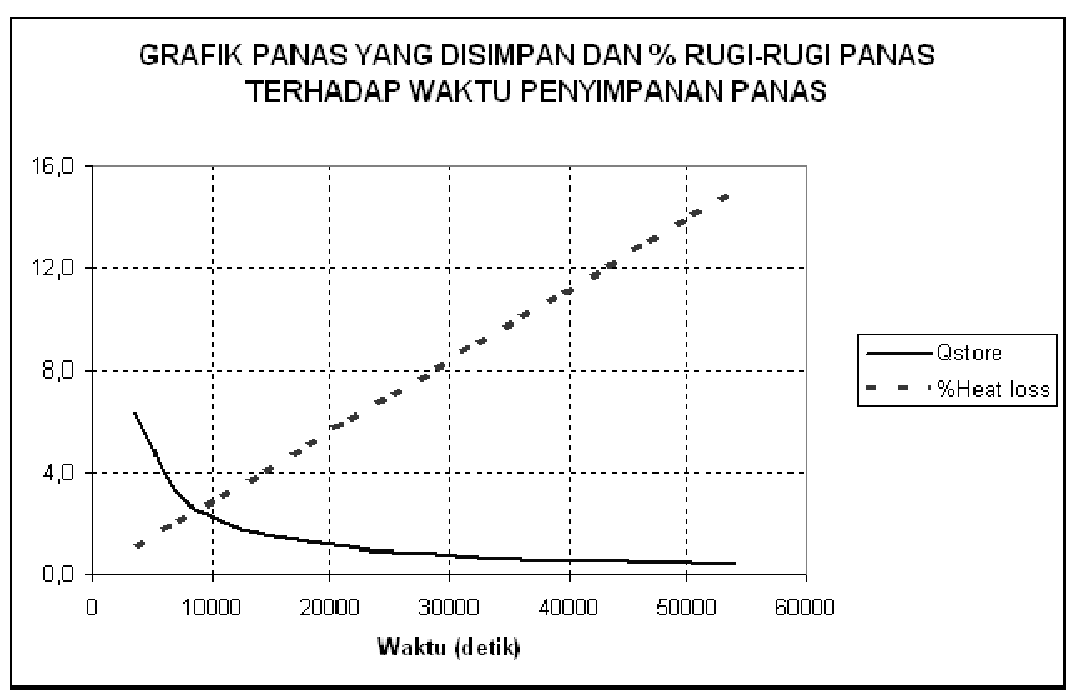

Gambar 6. Grafik panas yang disimpan dan \% heat loss vs waktu penyimpanan panas.

Gambar 5 menunjukkan grafik yang membandingkan antara tebal keramik terhadap rugi-rugi panas. Pada grafik tersebut, terlihat bahwa semakin tebal ceramic maka rugi-rugi panas yang dihasilkan semakin rendah. Hal ini terjadi karena tebal ceramic memiliki fungsi berbanding terbalik dengan rugi-rugi panas, sehingga semakin tebal isolasi yang digunakan maka nilai rugi-rugi panasnya akan menjadi rendah.

Gambar 6 yang menunjukkan grafik antara perbandingan panas yang disimpan serta persentase rugi-rugi panas terhadap waktu penyimpanan panas dapat dianalisis bahwa nilai panas yang disimpan di dalam tangki akan semakin kecil seiring dengan semakin lamanya dilakukan waktu penyimpanan. Hal ini mempengaruhi nilai rugi-rugi panas di dalam tangki, dimana rugi-rugi panas akan membesar seiring dengan waktu penyimpanan panas yang semakin lama.

\section{KESIMPULAN}

Analisis rugi-rugi panas pada tangki penyimpan panas dalam sistem pembangkit listrik tenaga matahari dengan diameter tangki $0,4 \mathrm{~m}$, tinggi tangki $0,45 \mathrm{~m}$ dan tebal ceramic 0,1 $\mathrm{m}$ menghasilkan kapasitas penyimpanan (daya) sebesar $0,53 \mathrm{~kW}$, tahanan termal total sebesar $3,47^{\circ} \mathrm{C} / \mathrm{W}$, rugi-rugi panas sebesar $63,43 \mathrm{~W}$, dan persentase kehilangan panas yang dihasilkan adalah $12 \%$. Thermo oil merupakan fluida penyimpan panas yang baik karena memiliki nilai panas spesifik yang tinggi, sehingga nilai kapasitas penyimpanan panas di dalam tangki menjadi besar. Ceramic merupakan bahan isolasi yang baik karena memiliki nilai konduktivitas termal yang rendah. Semakin tebal isolasi yang digunakan maka rugi-rugi panas yang dihasilkan akan semakin kecil, dan semakin lama waktu yang digunakan untuk menyimpan panas maka rugi-rugi panas yang dihasilkan akan semakin besar. 


\section{DAFTAR PUSTAKa}

[1] Wu, B., Reddy, R.G., Rogers, R.D., (2001, April), "Novel Ionic Liquid Thermal Storage For Solar Thermal Electric Power Systems", Proceedings of Solar Forum 2001, Washington D.C.

[2] Dracker, R., Rifflemann, K.J., (2008, July), "Integrated Thermal Storage For Concentrating Solar Power", Integrated Energy Policy Report Workshop July 31 2008, Solar Millennium LLC, Berkeley, CA.

[3] Muller, H., Steinhagen, (2008), "Solar Thermal Power Plants - On The Way to Commercial Market Introduction”, Institute for Technical Thermodynamics, German Aerospace Centre (DLR), Stuttgard - Cologne - Almeria/Spain.

[4] Firepro, (2008, August), "Ceramic Wool Blanket”, Firepro Centabuild Insulation, Auckland. [Online]. Available: http://www.firepro.co.nz.

[5] Solutia, (2001, July), "Therminol66: High Performance Highly Stable Heat Transfer Fluid”, Solutia Applied Chemistry, Creative Solutions, Europe. [Online]. Available: http//www.solutia.com.
[6] Incropera, F.P., De Witt, D.P., (1990), "Fundamentals of Heat and Mass Transfer", $3^{\text {rd }}$ edition, Singapore: John Wiley and Sons, Inc.

[7] Duffie, J.A., Beckman, B.A., (1991), "Solar Engineering of Thermal Processes", $2^{\text {nd }}$ edition, Singapore: John Wiley and Sons, Inc,.

[8] Blake, D.M., Moens, L., Hale, M.J., Price, H., Kearney, D., Hermann, U., (2002), "New Heat Transfer and Storage Fluids For Parabolic Trough Solar Thermal Electric Plants", Proceedings of the 11th SolarPACES International Symposium On concentrating Solar Power and Chemical Energy Technologies, Zurich, Switzerland.

[9] Tamme, R., Laing, D., Steinmann, W.D., (2003), “Advanced Thermal Energy Storage Technology For Parabolic Trough", Proceedings of ISEC 2003, 2003 International Solar Energy Conference, Hawaii, pp. 1-8. 